\section{A112 CD3/CD46-MEDIATED GENERATION OF IL-10-SECRETING T CELLS IS DEFECTIVE IN RHEUMATOID ARTHRITIS}

Gaelle Le Friec, ${ }^{1}$ John Cardone, ${ }^{1}$ Andrew Cope, ${ }^{2}$ Claudia Kemper ${ }^{1}{ }^{1} M R C$ Centre for Transplantation, King's College School of Medicine, King's College London, London UK; ${ }^{2}$ Academic Department of Rheumatology, King's College School of Medicine, King's College London, London UK

\subsection{6/ard.2010.148981.15}

Background and objectives Control of effector $T$ cell responses to foreign and self-antigens through interleukin (IL)-10-producing Th1 cells and adaptive IL-10+Tregs is vital for limiting immune pathology during infection and for preventing autoimmunity. However, the mechanisms that regulate their production remain incompletely understood. CD46 is the receptor for the $\mathrm{C} 3 \mathrm{~b} / \mathrm{C} 4 \mathrm{~b}$ components of complement. The authors have previously demonstrated that activation of human CD4 T cells through the T-cell receptor and the complement regulator CD46 induces Tr1 like IL-10-producing Tregs. The authors set out to study factors that regulate the generation of IL-10 producing Tregs during normal immune homeostasis and to determine whether this pathway is defective in chronic inflammatory disease, such as rheumatoid arthritis.

Materials and methods CD4 $\mathrm{T}$ lymphocytes were purified from PBMC of normal donors or PBMC and synovial fluid of rheumatoid arthritis (RA) and JIA patients using CD4 MicroBeads prior to activation with anti-CD3 and anti-CD46 $\mathrm{mAb}$ in the presence or absence of increasing concentrations of IL-2. After 36 h cytokine production was determined using the Th1/Th2 cytokine bead array. Cells were stained using the IFN $\gamma$ and IL-10 cytokine secretion assay kits in combination and IFN $\gamma^{+}$, IFN $\gamma^{+} / \mathrm{IL}-10^{+}$and IL- $10^{+}$cells isolated via cell sorting. Supernatants from cultures of these cells were then tested for their capacity to suppress proliferation of freshly purified T cells. Approval for this study was obtained from the Local Ethics Review Committee.

Results IL-10-secreting $T$ cells are derived from populations of differentiating Th1 effector $\mathrm{T}$ cells as they also secrete IFN $\gamma$. The authors observed that the cytokine expression profile of CD3/CD46-activated T cells is heavily influenced by the amount of IL- 2 present during activation. Thus, in the presence of low IL-2, CD3/CD46-activation induces strong IFN $\gamma$-secretion and a proinflammatory effector phenotype. High IL-2 induces a 'switch' from IFN $\gamma^{+} \mathrm{T}$ cells, via an IFN $\gamma^{+}$/ IL- $10^{+}$state, to an IL-10+ $1{ }^{+}$phenotype. CD46-induced IFN $\gamma^{+} /$ IL- $10^{+}$and IL- $10^{+}$cells are suppressive. By contrast, analysis of $T$ cell populations from patients with inflammatory arthritis such as RA and JIA reveals that progression to the IL- $10^{+}$state is blocked even in the presence of high exogenous IL-2. In addition, CD3/CD46-activated $\mathrm{T}$ cells produce $20-30$ times more IFN- $\gamma$ than IL-10.

Conclusions CD46 activation during T cell response initiation supports IFN $\gamma$ secretion to combat infection while expansion of the effector response provides high IL-2 and the signal to switch to IL-10 production and resolution of the immune response. This regulatory switch appears to be defective in chronic inflammatory disease. 